\title{
Synthesis of dihydrobenzodithiepines by the reactions of 1,2-dichloro- and 1-chloro-2-nitrobenzenes with 1,3-dithiols
}

\author{
G. I. Nikishin,* D. V. Demchuk, and A. V. Miroshnichenko \\ N. D. Zelinsky Institute of Organic Chemistry, Russian Academy of Sciences, \\ 47 Leninsky prosp., 119991 Moscow, Russian Federation \\ E-mail: nika@ioc.ac.ru
}

\section{Dedicated to Professor B. A. Trofimov on his $65^{\text {th }}$ birthday}

(received 31 May 03; accepted 17 Sept 03; published on the web 26 Sept 03)

\begin{abstract}
The reactions of nucleophilic substitution of the chlorine atoms and the nitro group in 1,2dichloro- and 1-chloro-2-nitrobenzenes 2 by the thiolate anions generated from 2,2-disubstituted 1,3-propanedithiols $\mathbf{1}$ under the action of bases afford dihydrobenzodithiepines $\mathbf{3}$.
\end{abstract}

Keywords: 1,3-Propanedithiol, 1,2-dichlorobenzene, 1-chloro-2-nitrobenzene, aromatic nucleophilic substitution, dihydrobenzodithiepines

\section{Introduction}

There are several examples of nucleophilic substitution of halogen in aryl halogenides by thiolate groups. ${ }^{1}$ The reactivity of non-activated phenyl halogenides decreases in the order $\mathrm{PhI}>\mathrm{PhF}>\mathrm{PhBr}>\mathrm{PhCl}^{2}{ }^{2}$ A different order has been observed for 1-halogen-2,4-dinitrobenzenes. ${ }^{3}$ Compared to substitutions with mono-thiolates, reactions between aliphatic or aromatic dithiolates and mono- or dihalogenoarenes have been poorly substituted. Examples of known reactions are the formation of benzodithianes from 1,2-di-iodobenzene and 1,2-ethanethiol, ${ }^{4}$ and of 1,1'-dinaphthyl-2,2'-ethanedithiol and 4,5-dichloro-1,2-dicyanobenzene, ${ }^{5}$ while condensation of 1,2-dimercaptobenzene with 1,2,3,4-tetra- and hexa-fluorobenzenes afforded benzodithianes with two or three dithiane rings. ${ }^{6}$

In the present work, which is aimed at synthesizing macrocyclic sulfides and thia-crown ethers, we report the first results of our study of nucleophilic substitution of the halogen atoms and the nitro group in the aromatic cycle by thiolate anions.

\section{Results and Discussion}


We first optimized the conditions for synthesis of the benzodithiepine $\mathbf{3 c}$ using the reaction of $\mathbf{1 b}$ with 2a. The results presented in Table 1 were obtained under the optimal conditions. The thiylation of the dichlorobenzene 2a with the dithiols 1a-c occurred under the action of sodium hydride in dimethylacetamide (DMA) solution at reactant concentrations of $\sim 0.1 \mathrm{M}$. The complete conversion of dithiols 1a-c (GLC monitoring) at $105^{\circ} \mathrm{C}$ took $6-9 \mathrm{~h}$ (Table 1). The trifluoromethyl group in the benzene ring activates the chlorine atoms, and the reaction of dichlorobenzene, $\mathbf{2 b}$, with dithiols $\mathbf{1 b}, \mathbf{c}$ occurred much more rapidly, and its selectivity was higher. The yield of dithiepines 1a-f varies from 48 to $99 \%$, depending on the substituents in reactants 1 and $\mathbf{2}$. The bulkier substituents in the dithiols $\mathbf{1 a - c}$ provide a higher yield of the target products. For example, the reaction of $\mathbf{1 c}$ with dichlorobenzene $\mathbf{2 b}$ affords the benzodithiepine $\mathbf{3 f}$ in $\sim 100 \%$ yield.

Table 1. Reaction of 1,2-dichloro- and 1,2-dichloro-4-trifluoromethylbenzenes 2a,b with 1,3propanedithiols 1a-c

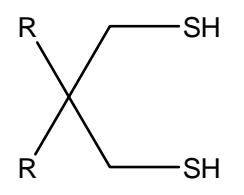

$\underline{1 a-c}$

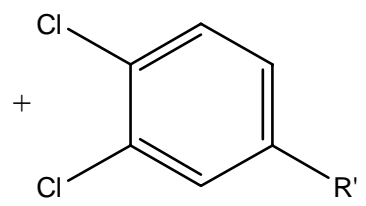

$\underline{\mathbf{2 a}, \mathbf{b}}$

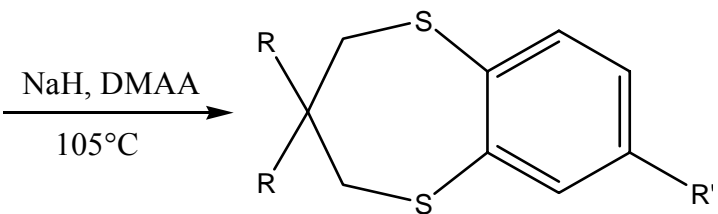

$\underline{\mathbf{3 a}-\mathbf{f}}$

$\begin{array}{ll}\underline{\mathbf{1 a}} \mathrm{R}=\mathrm{Me} & \underline{\mathbf{2 a}} \mathrm{R}^{\prime}=\mathrm{H} \\ \underline{\mathbf{1 b}} \mathrm{R}=\mathrm{Et} & \underline{\mathbf{2 b}} \mathrm{R}^{\prime}=\mathrm{CF}_{3} \\ \underline{\mathbf{c}} \mathrm{R}+\mathrm{R}=\left(\mathrm{CH}_{2}\right)_{5} & \end{array}$

$\underline{\mathbf{1 a}} \mathrm{R}=\mathrm{Me}$ $\underline{1 \mathbf{c}} \mathrm{R}+\mathrm{R}=\left(\mathrm{CH}_{2}\right)_{5}$

\begin{tabular}{ccccc}
\hline 1a-c & 2a,b & $\begin{array}{c}\text { Reaction } \\
\text { time, } \mathrm{h}\end{array}$ & $\mathbf{3 a}-\mathbf{f}$ & $\begin{array}{c}\text { Isolated } \\
\text { yield, } \%\end{array}$ \\
\hline $\mathbf{1 a}$ & $\mathbf{2 a}$ & 9 & $\mathbf{3 a}$ & 48 \\
$\mathbf{1 a}$ & $\mathbf{2 b}$ & 6 & $\mathbf{3 b}$ & 50 \\
$\mathbf{1 b}$ & $\mathbf{2 a}$ & 8 & $\mathbf{3 c}$ & 69 \\
$\mathbf{1 b}$ & $\mathbf{2 b}$ & 1.5 & $\mathbf{3 d}$ & 75 \\
$\mathbf{1 c}$ & $\mathbf{2 a}$ & 7 & $\mathbf{3 e}$ & 88 \\
$\mathbf{1 c}$ & $\mathbf{2 b}$ & 2 & $\mathbf{3 f}$ & 99 \\
\hline
\end{tabular}

Like the substituted dithiols 1a-c, unsubstituted 1,3-propanedithiol reacted readily with 2a. However, in this case, only resin-like substances, probably polycondensation products, were formed. In order to extend the range of starting reactants in the synthesis of $\mathbf{3 a}$ and $\mathbf{3 c}$, we used

$$
\begin{aligned}
& \underline{\mathbf{3 a}} \mathrm{R}=\mathrm{Me}, \mathrm{R}^{\prime}=\mathrm{H} \\
& \underline{\mathbf{3 b}} \mathrm{R}=\mathrm{Me}, \mathrm{R}^{\prime}=\mathrm{CF}_{3} \\
& \underline{\underline{\mathbf{3}}} \mathrm{R}=\mathrm{Et}, \mathrm{R}^{\prime}=\mathrm{H} \\
& \underline{\mathbf{3 d}} \mathrm{R}=\mathrm{Et}, \mathrm{R}^{\prime}=\mathrm{CF}_{3} \\
& \underline{\mathbf{3 e}} \mathrm{R}+\mathrm{R}=\left(\mathrm{CH}_{2}\right)_{5}, \mathrm{R}^{\prime}=\mathrm{H} \\
& \underline{\mathbf{3 f}} \mathrm{R}+\mathrm{R}=\left(\mathrm{CH}_{2}\right)_{5}, \mathrm{R}^{\prime}=\mathrm{CF}_{3}
\end{aligned}
$$


2a along with 1-chloro-2-nitrobenzene, 2c. However, this variant was inappropriate under the conditions presented in Table 1 because of the low yield of the target products and side reactions. The selectivity of the reaction was enhanced using the one-pot synthesis in two steps. In the first step, the thiolate anion substituted only the chlorine atom in $\mathbf{2 c}$ under the action of the weak base $\mathrm{NaHCO}_{3}$. This resulted in the formation of intermediate thiol 4 (Scheme 1), which was isolated and identified $(\mathbf{4 b}, \mathrm{R}=\mathrm{Et})$ in one of the experiments. In the second step, $\mathrm{KOH}$ was introduced into the reaction mixture without isolating the thiol $\mathbf{4}$, and the process formed the dithiepines 3a,c by intramolecular substitution of the nitro group by the thiolate anion.

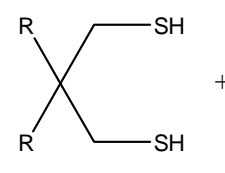

$\underline{\mathbf{1 a}, \mathbf{b}}$

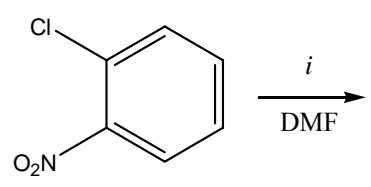

$\underline{2 \mathrm{c}}$
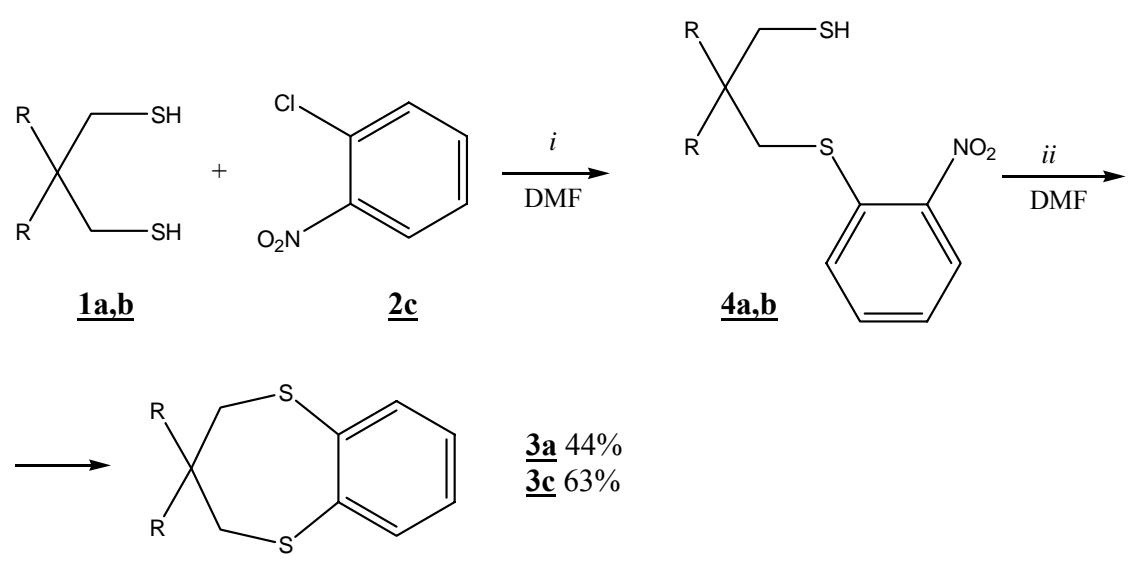

Reaction conditions: $i \mathrm{NaHCO}_{3}, \underline{\mathbf{1 a}} 50^{\circ} \mathrm{C}, 7 \mathrm{~h} ; \mathrm{NaHCO}_{3}, \underline{\mathbf{1 b}} 60^{\circ} \mathrm{C} 7 \mathrm{~h}$. ii $\mathrm{KOH}, \underline{\mathbf{1 a}} 50^{\circ} \mathrm{C}, 1 \mathrm{~h} ; \underline{\mathbf{1 b}} 60^{\circ} \mathrm{C}, 1,5$.

\section{Scheme 1}

The reaction of the dithiols 1a,b with 1,2-dichloro-4-nitrobenzene 2d (Scheme 2) was performed similarly. In the two-step variant, we succeeded in decreasing the probability of substitution of the nitro group in $\mathbf{2 d}$ by the thiolate anion. The benzodithiepines $\mathbf{3 g}$, $\mathbf{h}$ containing the nitro group in the aromatic ring were prepared in satisfactory yields.

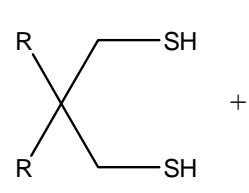

$\underline{\mathbf{a}, \mathbf{b}}$

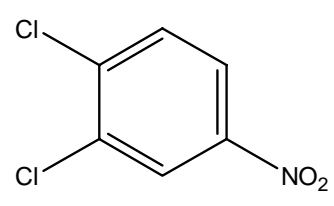

$\underline{2 \mathbf{d}}$

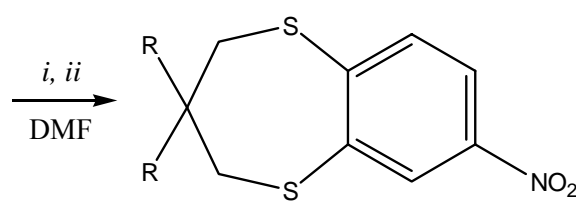

$\underline{\text { 3g }} \mathrm{R}=\mathrm{Me}(54 \%)$ $\underline{\text { 3h }} \mathrm{R}=$ Et $(48 \%)$

Reaction conditions: $i \mathrm{NaHCO}_{3}, \underline{\mathbf{1 a}} 60^{\circ} \mathrm{C}, 7 \mathrm{~h} ; \mathrm{NaHCO}_{3}, \underline{\mathbf{1 b}} 50^{\circ} \mathrm{C} 7 \mathrm{~h}$. ii $\mathrm{KOH}, \underline{\mathbf{1 a}} 60^{\circ} \mathrm{C}, 1 \mathrm{~h} ; \underline{\mathbf{1 b}} 50^{\circ} \mathrm{C}, 1,5$.

\section{Scheme 2}


The structures of compounds $\mathbf{3 a}-\mathbf{h}$ were proved by ${ }^{1} \mathrm{H}$ - and ${ }^{13} \mathrm{C}$ - NMR spectra, elemental analysis, and mass spectra.

\section{Summary}

The simple and convenient one-pot synthesis of new benzodithiepines 3a-h was developed on the basis of aromatic nucleophilic reactions of 2-substituted 1,3-propanedithiols 1 with easily accessible 1,2-dichloro- and 1-chloro-2-nitrobenzenes. The reaction occurred under the action of bases at a ratio of reactants close to stoichiometric. The yields of dihydrobenzodithiepines 3 ranged from $48 \%$ to $\sim 100 \%$, depending on the character of substituents in the starting reactants. In the synthesis of $\mathbf{3}$ we also used 1,2-dichloro-4-trifluoromethyl and 1,2-dichloro-4nitrobenzene.

\section{Experimental Section}

General Procedures. GLC analysis was carried out on a Chrom 5 chromatograph with a flameionization detector and a column $3 \mathrm{~m} \times 3 \mathrm{~mm}$ using Chromaton $\mathrm{N}$-super $(0.160-0.200 \mathrm{~mm})$ as the sorbent with the SE-Superphase (5\%) liquid phase. NMR spectra of solutions in $\mathrm{CDCl}_{3}$ were recorded on Bruker AC-200, Bruker WM-250, and Bruker AM300 spectrometers. Coupling constants $(\mathrm{J})$ were reported in Hz. NMR chemical shifts, $\delta$ were expressed in ppm, and were related to the internal solvent peak. Mass spectra were obtained on a Kratos-MS30 instrument. Silica gel $60(0.063-0.200 \mathrm{~mm})$ Merck was used in column chromatography. TLC analysis was carried out on Sorbfil plates. Melting points were determined on a Kofler hot-stage apparatus.

\section{Starting reactants}

1,2-Dichlorobenzene, 1-chloro-2-nitrobenzene, 1,2-dichloro-4-nitrobenzene, and 1,2-dichloro-4trifluoromethylbenzene were commercial compounds, used without further purification. 2,2Dimethyl-1,3-propanedithiol, 2,2-diethyl-1,3-propanedithiol, and 2,2-pentamethylene-1,3propanedithiol were prepared according to known procedures. ${ }^{7}$

\section{Reaction of propanedithiols 1a-c with dichlorobenzenes, 2a,b, Preparation of compounds} 3a-3f

\section{General procedure 1 (Table 1)}

95\% $\mathrm{NaH}$ (96 mg, $3.8 \mathrm{mmol})$ was added with stirring to the dithiol 1 (1.5 mmol) in DMA (20 $\mathrm{ml})$, under argon. The reaction mixture was heated to $105^{\circ} \mathrm{C}$, a solution of 1,2-dichlorobenzene 2 $(1.8 \mathrm{mmol})$ in DMA $(5 \mathrm{ml})$ was added, and the mixture kept at this temperature to the end of the reaction, (monitored by GLC of the content of dithiol 1). The reaction mixture was cooled, poured into water $(250 \mathrm{ml})$, acidified (conc. $\mathrm{HCl}, 0.5 \mathrm{ml}, 5.5 \mathrm{mmol}$ ), and extracted with 
petroleum $(4 \times 10 \mathrm{ml})$. The extract was washed with water $(2 \times 15 \mathrm{ml})$, dried with $\mathrm{MgSO}_{4}$, the solvent evaporated, and the product isolated by column chromatography ( $\mathrm{SiO}_{2} /$ petroleum).

3,3-Dimethyl-3,4-dihydro-2H-1,5-benzodithiepine (3a). The dithiol $\mathbf{1 a}(204 \mathrm{mg})$ and dichlorobenzene $2 \mathrm{a}(265 \mathrm{mg})$ gave $\mathbf{3 a}^{8}(152 \mathrm{mg}, 48 \%)$ as a colorless oil. ${ }^{1} \mathrm{H}$ NMR $(250 \mathrm{MHz})$ $1.17(\mathrm{~s}, 6 \mathrm{H}), 2.80(\mathrm{~s}, 4 \mathrm{H}), 7.08(\mathrm{~m}, 2 \mathrm{H}) 7.44(\mathrm{~m}, 2 \mathrm{H})$.

3,3-Dimethyl-7-trifluoromethyl-3,4-dihydro-2H-1,5-benzodithiepine (3b). The dithiol 1a (204 mg) and 1,2-dichloro-4-trifluoromethylbenzene 2b (387 mg) gave 3b (209 mg, 50\%) as colorless crystals, m.p. $67.5-68.3^{\circ} \mathrm{C} .{ }^{1} \mathrm{H}$ NMR $(250 \mathrm{MHz}) \delta 1.21(\mathrm{~s}, 6 \mathrm{H}), 2.97(\mathrm{~s}, 4 \mathrm{H}), 7.28(\mathrm{~d}, \mathrm{~J}$ $2.63 \mathrm{~Hz}, 1 \mathrm{H}) 7.46(\mathrm{~d}, \mathrm{~J} 7.88 \mathrm{~Hz}, 1 \mathrm{H}), 7.62(\mathrm{~s}, 1 \mathrm{H}) ;{ }^{13} \mathrm{C} \mathrm{NMR}(75.47 \mathrm{MHz}) \delta \quad 26.7,35.4,44.2$, 123.3, 128.9, 132.2, 129.0, 124.00 (q, J 180); m/z $278[\mathrm{M}]^{+}$; Anal. Calcd. for $\mathrm{C}_{12} \mathrm{H}_{13} \mathrm{~F}_{3} \mathrm{~S}_{2}$ (278.36): C 51.73, H 4.67, found: C 51.74, H 4.59\%.

3,3-Diethyl-3,4-dihydro-2H-1,5-benzodithiepine (3c). The dithiol $\mathbf{1 b}(247 \mathrm{mg})$ and dichlorobenzene 2a (265 mg) gave 3c (246 mg, 69\%) as colorless crystals; m.p. 43.5-44.5 ${ }^{\circ} \mathrm{C} .{ }^{1} \mathrm{H}$ NMR (250 MHz) 0.83 (t, J 7.72, 6H), 1.58 (q, J 7.72, 4H), 2.87 (s, 4H), 7.02-7.13 (m, 2H) 7.357.43 (m, 2H) ${ }^{13} \mathrm{C}$ NMR (75.47 MHz) 7.7, 26.8, 37.9, 41.1, 120.7, 126.8, 132.2; m/z $238[\mathrm{M}]^{+}$; Anal. Calcd. for $\mathrm{C}_{13} \mathrm{H}_{18} \mathrm{~S}_{2}$ (238.41): C 65.49, H 7.61, S 26.90, found: C 65.59, H 7.54, S 26.67\%. 3,3-Diethyl-7-trifluoromethyl-3,4-dihydro-2H-1,5-benzodithiepine (3d). The dithiol 1 b (247 $\mathrm{mg})$ and 3,4-dichloro-1-trifluoromethylbenzene $\mathbf{2 b}(387 \mathrm{mg})$ gave $\mathbf{3 d}(345 \mathrm{mg}, 75 \%)$ as colorless crystals, m.p. $78.7-80.4^{\circ} \mathrm{C} .{ }^{1} \mathrm{H}$ NMR $(250 \mathrm{MHz}) \delta 0.85$ (t, J 7.50, 6H), 1.56 (q, J 7.50, 4H), 3.00 (s, 4H), 7.25 (d, J 8.46, 2H) 7.40 (d, J 8.46, 2H) 7.43 (s, 1H) ${ }^{13} \mathrm{C}$ NMR (75.47 MHz) 24.4, 37.9, $38.3,38.5,120.7,126.3,115.2-129.0$ (q, J 180) 129.6, 126.4; m/z 306 [M] ${ }^{+}$; Anal. Calcd. for $\mathrm{C}_{14} \mathrm{H}_{17} \mathrm{~F}_{3} \mathrm{~S}_{2}$ (306.41): C 54.90, H 5.56, found: C 55.15, H 5.76\%.

3-Spirocyclohexane-3,4-dihydro-2H-benzo-1,5-dithiepine (3e). The dithiol 1c (264 mg) and dichlorobenzene $\mathbf{2 a}(265 \mathrm{mg})$ gave $3 \mathbf{e}(330 \mathrm{mg}, 88.0 \%)$ as a colorless oil. ${ }^{1} \mathrm{H}$ NMR $(250 \mathrm{MHz}) \delta$ $0.97(\mathrm{~m}, 5 \mathrm{H}), 2.37(\mathrm{~m}, 5 \mathrm{H}), 2.93(\mathrm{~s}, 4 \mathrm{H}), 7.27,7.21,7.24(\mathrm{~m}, 2 \mathrm{H}), 7.66-7.73(\mathrm{~m}, 2 \mathrm{H}),{ }^{13} \mathrm{C}$ NMR $(75.47 \mathrm{MHz}) 22.1,24.3,26.6,35.2,42.6,129.0,127.1,132.6 ; \mathrm{m} / \mathrm{z} 250[\mathrm{M}]^{+}$Anal. Calcd. for $\mathrm{C}_{14} \mathrm{H}_{18} \mathrm{~S}_{2}$ (250.43): C 67.15, H 7.24, S 25.61, Found: C 67.27, H 7.19, S 25.67\%.

7-Trifluoromethyl-3-spirocyclohexane-3,4-dihidro-2H-benzo-1,5-dithiepine (3f). The dithiol 1c (264 mg) and 3,4-dichloro-1-trifluoromethylbenzene $\mathbf{2 b}(387 \mathrm{mg})$ gave $\mathbf{3 f}(473 \mathrm{mg}, 99.0 \%)$ as colorless crystals; m.p. 81.0-82.5 ${ }^{\circ} \mathrm{C} .{ }^{1} \mathrm{H}$ NMR $(250 \mathrm{MHz}) 1.45-1.58(\mathrm{~m}, 10 \mathrm{H}), 3.07(\mathrm{~s}, 4 \mathrm{H}), 7.22$ (d, J 8.09, 2H) 7.37 (d, J 8.09, 1H) 7.53 (s, 1H) ${ }^{13} \mathrm{C}$ NMR (75.47 MHz) 21.8, 26.1, 26.1,34.7, 37.2, 41.5, 41.7, 122.9, 119.0- 130.0(q, J 180) 131.8; m/z $318[\mathrm{M}]^{+}$. Anal. Calcd. for $\mathrm{C}_{15} \mathrm{H}_{17} \mathrm{~F}_{3} \mathrm{~S}_{2}$ (318.42): C 56.58, H 5.48, found: C 56.45, H 5.40\%.

Preparation of 2-Ethyl-2-\{[(2-nitrophenyl)thia]methyl\}-1-butanethiol (4b). $\mathrm{NaHCO}_{3}(129$ $\mathrm{mg}, 0.82 \mathrm{mmol})$ and then a solution of the chloronitrobenzene $2 \mathrm{c}(129 \mathrm{mg}, 0.82 \mathrm{mmol})$ in DMF $(4 \mathrm{ml})$ were added with stirring to $90 \%$ of the dithiol $\mathbf{1 b}(150 \mathrm{mg}, 0.82 \mathrm{mmol})$ in absolute DMF $(8 \mathrm{ml})$ under argon. The reaction mixture was kept at $50^{\circ} \mathrm{C}$, to the complete conversion of dithiol 1b. After $7 \mathrm{~h}$, the mixture was poured into water $(150 \mathrm{ml})$, acidified (conc. $\mathrm{HCl}, 2 \mathrm{ml}, 22 \mathrm{mmol}$ ), and extracted with toluene $(3 \times 10 \mathrm{ml})$. The extract was washed with water $(2 \times 20 \mathrm{ml})$, dried with 
$\mathrm{MgSO}_{4}$, evaporated, and the product isolated by column chromatography $\left(\mathrm{SiO}_{2} /\right.$ toluenepetroleum, 1:1). Compound $\mathbf{4 b}$ was obtained in 70\% yield $(164 \mathrm{mg})$ as yellow crystals; m.p.

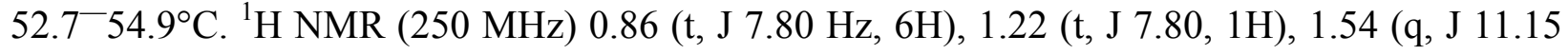
$\mathrm{Hz}, 2 \mathrm{H}), 2.65$ (d, J 11.15, 2H), 2.93 (s, 2H), 7.26 (t, J 6.55, 1H), 7.49-7.52 (m, 2H), 8.18 (d, J 7.50, 1H). ${ }^{13} \mathrm{C}$ NMR (63 MHz) 7.56, 26.67, 30.59, 37.9, 40.35, 124.45, 125.95, 127.23, 133.39, 137.90. Anal. Calcd. for $\mathrm{C}_{13} \mathrm{H}_{19} \mathrm{NO}_{2} \mathrm{~S}_{2}$ (285.43): C 54.70, H 6.71, S 2.25, found: C 54.73, H 6.88, S $2.23 \%$.

Reaction of propanedithiols 1a,b with 2-chloronitrobenzene, 2c, and 3,4-dichloronitrobenzene, 2d. Preparation of compounds 3a, 3c, 3g, 3h

General procedure 2 (Schemes 1,2)

$\mathrm{NaHCO}_{3}(69 \mathrm{mg}, 0.82 \mathrm{mmol})$ and then a solution of $\mathbf{2 c}$ or $\mathbf{2 d}(0.82 \mathrm{mmol})$ in DMF (4 ml) were added with stirring to the dithiol $1(0.82 \mathrm{mmol})$ in dry DMF $(8 \mathrm{ml})$ under argon. The mixture was stored at $60^{\circ} \mathrm{C}$ until complete conversion of 1 . Then $\mathrm{KOH}(46 \mathrm{mg}, 0.70 \mathrm{mmol})$ was added, and the mixture stirred at $50^{\circ} \mathrm{C}$. The reaction mixture was poured into water $(150 \mathrm{ml})$, acidified (conc. $\mathrm{HCl}, 2 \mathrm{ml})$, and extracted with petroleum $(3 \times 10 \mathrm{ml})$. The extract was washed with water $(2 \times 20 \mathrm{ml})$, dried with $\mathrm{MgSO}_{4}$, the solvent evaporated, and the product isolated by column chromatography $\left(\mathrm{SiO}_{2}\right)$. The fractions containing 3 were collected.

3,3-Dimethyl-3,4-dihydro-2H-1,5-benzodithiepine (3a). The dithiol 1a (112 mg) and 2-chloronitrobenzene 2c (129 mg) gave 3a (83 mg, 44\%). Petroleum was used as the eluent.

3,3-Diethyl-3,4-dihydro-2H-1,5-benzodithiepine, (3c). The Dithiol 1b (135 mg) and 2-chloronitrobenzene 2c (129 mg) gave 3c (135 mg, 63\%); m.p. 43.5-44.5 ${ }^{\circ} \mathrm{C}$. Petroleum was used as the eluent.

3,3-Dimethyl-7-nitro-3,4-dihydro-2H-1,5-benzodithiepine (3g). The dithiol 1a (112 mg) and 3,4-dichloronitrobenzene $2 \mathbf{d}(157 \mathrm{mg})$ gave $3 \mathrm{~g}$ (106 mg, $54 \%$ ) as yellow crystals, m.p. 151$152.3^{\circ} \mathrm{C}$. Toluene-petroleum (1:1) was used as eluent. ${ }^{1} \mathrm{H}$ NMR $(250 \mathrm{MHz}) 1.42(\mathrm{~s}, 6 \mathrm{H}), 3.1(\mathrm{~s}$, 4H), 7.36 (d, J 8.53), 8.05 (dd, $\left.\mathrm{J}_{1} 8.53, \mathrm{~J}_{2} 2.63,1 \mathrm{H}\right), 8.10$ (d, J 2.63, 1H). ${ }^{13} \mathrm{C}$ NMR $(50.32 \mathrm{MHz})$ 27.25, 36.30, 43.30, 121.91, 124.32, 125.88, 132.36, 144.95, 146.27. Anal. Calcd. for $\mathrm{C}_{11} \mathrm{H}_{13} \mathrm{NO}_{2} \mathrm{~S}_{2}$ (255.36): C 51.74, H 5.13, S 25.11, found: C 51.86, H 5.21, S 24.96\%.

3,3-Diethyl-7-nitro-3,4-dihydro-2H-1,5-benzodithiepine (3h). The dithiol $\mathbf{1 b}(135 \mathrm{mg})$ and 3,4-dichloronitrobenzene $\mathbf{2 d}(157 \mathrm{mg})$ gave $\mathbf{3 h}(135 \mathrm{mg}, 48 \%)$ as yellow crystals; m.p. 82.0$83.4^{\circ} \mathrm{C}$. A toluene-petroleum $(1: 1)$ mixture was used as eluent. ${ }^{1} \mathrm{H}$ NMR $(250 \mathrm{MHz}) 0.85$ (t, J $7.356 \mathrm{H}), 1.59$ (q, J $7.354 \mathrm{H}), 3.0$ (s, 2H), 3.2 (s, 2H), $7.34\left(\mathrm{dd}, \mathrm{J}_{1} 8.82, \mathrm{~J}_{2} 1.47,1 \mathrm{H}, \mathrm{H}_{3}\right), 7.60$ $\left(\mathrm{dd}, \mathrm{J}_{1} 8.82, \mathrm{~J}_{2} 1.47,2 \mathrm{H}, \mathrm{H}_{2}\right.$ ), 8.10 (d, J 1.47, 1H, H-1). ${ }^{13} \mathrm{C}$ NMR (50.32 MHz) 7.88, 26,33, 40.20, 39.98, 40.43, 120.62, 126.13, 131.19, 137.36, 144.95, 145.57. Anal. Calcd. for $\mathrm{C}_{13} \mathrm{H}_{17} \mathrm{NO}_{2} \mathrm{~S}_{2}$ (283.41): C 55.09, H 6.04, S 22.63, found: C 55.21, H 6.10, S 22.46\%.

\section{Acknowledgments}


This work was supported by the Federal Program on Support of Leading Scientific Schools (Grant 2121.2003.3).

\section{References}

1. Rybakova ,I. A.; Prilezhaeva, E. N.; Litvinov, V. P. Russ. Chem. Rev. 1991, 60, 1331.

2. Cogolli, P.; Maiolo, F.; Testaferri, L.; Tingoli, M.; Tiecco, M. J. Org. Chem. 1979, 44, 2642.

3. Bennett, J. F.; Merritt, W. D. Jr. J. Am. Chem. Soc. 1957, 79, 5967.

4. Pierini, A. B.; Baumgartner, M. T.; Rossi, R. A. J. Org. Chem. 1987, 52, 1089.

5. Kobayashi, N.; Higashi, R.; Titeca, B.C.; Lamote, F.; Ceulemans, A. J. Am. Chem. Soc. 1999, 121, 12018.

6. Nabeshima T., Furukawa N., Ishizawa T., Morihashi K., Kakuchi O. Heterocycles 1990, 31, 1575 .

7. Eliel, E. L.; Rao, V. S.; Smith, S.; Hotchins, R. O. J. Org. Chem. 1975, 40, 524.

8. Menard, D.; St. Jacques Can. J. Chem. 1986, 64, 2142. 